\title{
Comparison of Different PCR Methods for Detection of Brucella spp. in Human Blood Samples
}

\author{
HISHAM H. AL-AJLAN, ABDELNASSER S.S. IBRAHIM* and ALI A. AL-SALAMAH \\ Medical Unit, Department of Botany and Microbiology, Faculty of Science \\ King Saud University, P.O. 2454, Riyadh 11451, Saudi Arabia
}

Received 2 July 2010, revised 15 December 2010, accepted 18 December 2010

\begin{abstract}
For detection of Brucella species by PCR four DNA extraction methods and four targets were compared using pure culture of Brucella melitensis and the best conditions were applied in clinical samples. It was found that the MagNA Pure LC method was the most efficient and sensitive method showing a positive PCR reaction with DNA extracted from as low as 25 and 100 CFU suspended in one ml blood and one $\mathrm{ml}$ water, respectively. Detection of Brucella spp. by conventional PCR was investigated using four different targets. The results indicated that The B4-B5 amplification method was the most sensitive one as it could amplify DNA extracted from as a low as 25 and $100 \mathrm{CFU} / \mathrm{ml}$ suspended in one $\mathrm{ml}$ water and blood, respectively. Furthermore real-time PCR was able to detect Brucella using DNA extracted from as low as $50 \mathrm{CFU} / \mathrm{ml}$ blood and $15 \mathrm{CFU} / \mathrm{ml}$ water, respectively. The best and optimum detection conditions were applied to the clinical samples. Evaluation of conventional PCR assays on blood specimens confirmed $72 \%$ of the results obtained by conventional blood culture methods with a specificity of $95 \%$, while serum samples had a sensitivity of $54 \%$ and specificity of $100 \%$. Real-time PCR was generally found to be more sensitive and specific for detecting Brucella spp. in blood and serum samples compared to conventional PCR. The real-time PCR done on blood specimens confirmed $77.5 \%$ of the results obtained by conventional blood culture methods with specificity of $100 \%$, while $60 \%$ of serum samples were found to be positive with specificity of $100 \%$. These results suggest that serum and blood analysis by conventional and real time PCR is a convenient and safe method for rapid and accurate diagnosis of brucellosis.
\end{abstract}

K e y w ord s: Brucella spp., brucellosis, detection, PCR methods for detection

\section{Introduction}

Brucellosis is a major zoonotic disease that causes a serious health and economic problem worldwide (Elfaki et al., 2005). In spite of the growing number of countries declared Brucella-free, the disease remains one of the main zoonotic infections throughout many parts of the world with major economical and public health implications. About 500,000 new cases occur annually worldwide, with predominance in the Middle East, Mediterranean countries, South America and Central Asia (Godfroid, 2002; Sauret and Villissova, 2002). The causative organisms of brucellosis are Gram-negative facultative intracellular pathogens that may affect a range of different mammals including man, cattle, sheep, goats, swine, rodents and marine mammals and in most host species, the disease primarily affects the reproductive system with concomitant loss in productivity of animals affected (Cutler et al.,
2005). In man, infection is associated with protean manifestations and characteristically recurrent febrile episodes that led to the description of this disease as undulant fever (Abdoel et al., 2008). Currently, the diagnosis of brucellosis is based on microbiological and serological laboratory tests. However the diagnostic value of serological tests is unsatisfactory in the early stages of the disease due to low sensitivity, serological cross-reactions, and the inability to distinguish between active and inactive infection due to antibody persistence after therapy (Diaz and Moriyo, 1989; Navarro et al., 2002). Furthermore in patients with persistent or relapsing brucellosis, dependance on blood culture analysis is usually impeded by the low yield of microorganisms as a result of dormancy of brucellae in the mononuclear phagocytic cells (Elfaki et al., 2005). Blood cultures (which represent the 'gold standard' of laboratory diagnosis) are among the most important tests used for the diagnosis of infectious

* Corresponding author: A.S.S. Ibrahim, Department of Botany and Microbiology, Faculty of Science, King Saud University, P.O. 2454, Riyadh 11451, Saudi Arabia; phone: +96 6597359415; e-mail: ashebl@ksu.edu.sa 
diseases including brucellosis. However, contamination with skin type flora like coagulase negative staphylococcus could over grow the slow growing organisms like Brucella in addition to a serious threat to laboratory personnel (Yagupsky, 1999; 2004). Therefore, other diagnostic methods are needed to overcome such limitations of conventional approaches for the diagnosis of brucellosis. DNA-based methods such as gene probes and polymerase chain reaction (PCR) are attractive means for the confirmation of brucellosis. Because of the prevalence of brucellosis in Saudi Arabia, a precise diagnostic method should be established for the control of brucellae in this population. Different target genes, primer pairs, PCR techniques and extraction procedures have been previously investigated for Brucella detection, however, most of these assays have used Brucella DNA of pure cultures and only a few of these primers have been used in clinical animal, and human samples (Zerva et al., 2001; Abdoel et al., 2008; Bogdanovich et al., 2008; Hinić et al., 2008) and there is no enough report about comparison of these assays. Therefore the aims of the current work were to compare different DNA extraction method for DNA purification from Brucella cells, compare different targets and PCR methods for detection of Brucella and apply it to clinical human samples

\section{Experimental}

\section{Material and Methods}

Clinical samples and bacterial strains. A total of 200 clinical blood specimens were collected from the Armed Forces Hospitals (Riyadh, Saudi Arabia) including 160 blood samples obtained from patients with clinically proven or suspected systemic brucellosis infection and 40 control samples from healthy subjects without any clinical evidence or history of brucellosis. The diagnosis of brucellosis was confirmed by isolation and identification of Brucella spp. from blood culture. Blood ( 8 to $10 \mathrm{ml}$ ) was inoculated into BACTEC Plus aerobic/F blood culture bottle (enriched soybean-casein digest broth) and incubated for 28 days or until the bottles were positive. All blood cultures were evaluated in the BACTEC 9600 blood culture system (Becton Dickinson Diagnostic Instrument Systems), which detect microbial growth by continuous monitoring. One $\mathrm{ml}$ aliquots from bottles shown to contain Gram-negative coccobacilli bacteria were removed and stored at $-80^{\circ} \mathrm{C}$ until use. All isolated strains were identified in the lab. The reference strain used in this study was Brucella melitensis $16 \mathrm{M}$, which was obtained from the Central Veterinary laboratory (Weybridge, UK). It was propagated on chocolate agar (Oxoid) me- dium and incubated at $37^{\circ} \mathrm{C}$ in a humidified atmosphere supplemented with $5 \% \mathrm{CO}_{2}$. Brain heart infusion broth (Oxoid) with $20 \%$ glycerol (Sigma) was used for the storage of bacterial strains at $-80^{\circ} \mathrm{C}$.

Preparation of bacterial cells suspensions. Freshly cultured Brucella melitensis was killed by the addition of $70 \%$ methanol in sterile saline $(0.9 \%$ $\mathrm{NaCl}$ ) and recovered by centrifugation at $5000 \mathrm{rpm}$ for $5 \mathrm{~min}$, washed twice with $5 \mathrm{ml}$ of sterile distilled water then recovered by centrifugation at $5000 \mathrm{rpm}$ for $5 \mathrm{~min}$. The cells were serially diluted with sterile distilled water and adjusted to a $0.5 \mathrm{McF}$ arland standard (which is approximately $1.5 \times 10^{8} \mathrm{CFU} / \mathrm{ml}$ ). Different cell dilutions were prepared and suspended in either sterile distilled water or whole blood collected in EDTA Vacutainer from healthy individual with no evidence or history of brucellosis infection, to give a final cell count in the range of 25 to $10^{5} \mathrm{CFU} / \mathrm{ml}$. The inoculated whole blood samples and cells suspended in water were subsequently used for DNA extraction. Sterile water inoculated blood samples served as a negative control.

Bacterial DNA extraction methods. Four different DNA extraction kits were used to extract the genomic DNA of Brucella melitensis according to the manufacturer instructions including QIAmp kit (Qiagen), GenomicPrep DNA Isolation Kit (Amersham Biosciences), Automated Nucleic Acid Purification system (MagNA Pure LC Systems), in addition to $10 \%$ Chelex-100 resin suspension (Bio-Rad Laboratories) where $0.2 \mathrm{ml}$ cell suspension was mixed with $0.1 \mathrm{ml}$ of a 10\% Chelex-100 resin suspension (Bio-Rad Laboratories), and the mixture was boiled for $10 \mathrm{~min}$. After centrifugation at $10000 \mathrm{rpm}$ for $5 \mathrm{~min}$, about $0.1 \mathrm{ml}$ of supernatant was removed and used for PCR.

Detection of Brucella melitensis by conventional PCR. The sensitivity of conventional PCR was investigated for detection of Brucella melitensis using a modification of previously reported methods (Navarro et al., 2002; Baddour and Alkhalifa, 2008) using four different primers pairs (TIB MOLBIOL, Berlin, Germany), specific to four different targets in Brucella spp. (Table I). The PCR reaction contained $(25 \mu 1)$ : reaction buffer $\left(50 \mathrm{mM} \mathrm{KCl}, 1.5 \mathrm{mM} \mathrm{MgCl}_{2}, 10 \mathrm{mM}\right.$ Tris $\mathrm{HCl}, \mathrm{pH} 9.0), 200 \mu \mathrm{M}$ of each of dATP, dCTP, dGTP, and dTTP and $2.5 \mathrm{U}$ of puReTaq DNA polymerase (Amersham-Pharmacia). For optimization of PCR conditions different concentrations of primers (5-25 pmol) and $\mathrm{MgCl}_{2}(1.5-4 \mathrm{mM})$, amplification at different temperature settings and cycling programs were used (Table I). Following PCR reaction, $10 \mu \mathrm{l}$ of the reaction mixture was mixed with $2 \mu 1$ of loading buffer ReddyRun (ABgene) and was run in $2 \%$ agarose gel electrophoresed in Tris-borate-EDTA buffer (TBE) at $120 \mathrm{~V}$ for about $50 \mathrm{~min}$ and the amplified DNA bands were visualized in ethidium bromide staining and 


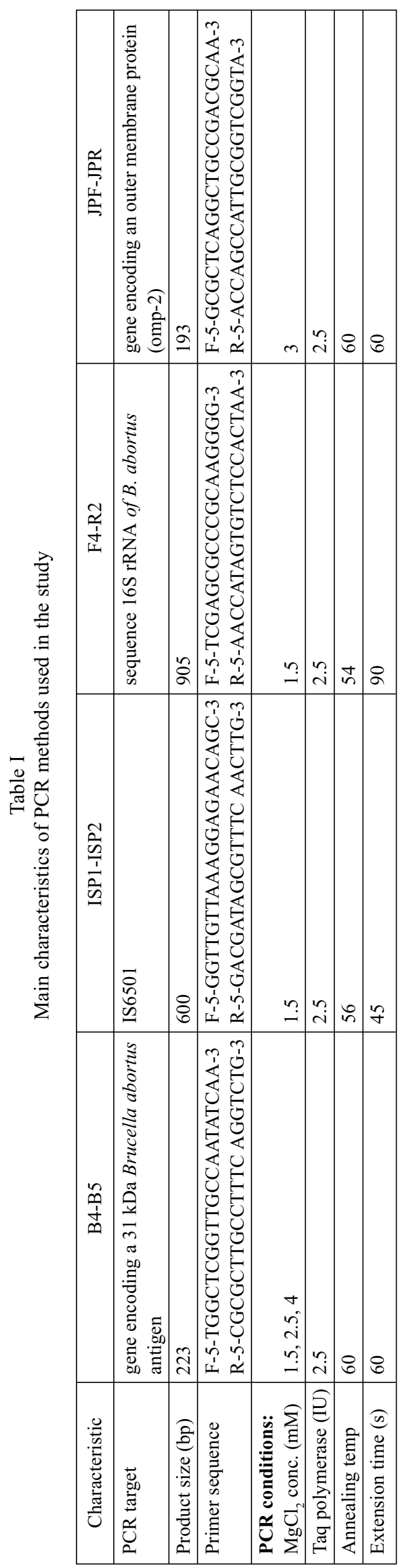

photographed under UV light. 100 bp Superladder (ABgene) was used as DNA Marker. Sterile water instead of DNA was used as a negative control.

Detection of Brucella melitensis by Real-time PCR. Detection of Brucella using Real-time PCR was investigated using modified of previously reported method (Redkar et al., 2001). The reaction mixture for the real time contained $2 \mu 1$ of 10x LightCycler-FastStart DNA master hybridization probes (Roche Diagnostics), $2.4 \mu \mathrm{MgCl}_{2}$ (final concentration of $4 \mathrm{mM}$ ), $4 \mu \mathrm{l}$ Reagent mix (Brucella-specific primers and hybridization probes), and $6.6 \mu 1$ nucleases free water and $5 \mu \mathrm{l}$ of the tested DNA. Thermocycling conditions were as follows: one cycle of initial denaturation at $95^{\circ} \mathrm{C}$ for $10 \mathrm{~min}$, followed by 55 amplification cycles (temperature transition rate of $20^{\circ} \mathrm{C} / \mathrm{s}$ ), each including denaturation $\left(95^{\circ} \mathrm{C}\right.$ for $\left.10 \mathrm{~s}\right)$, annealing $\left(55^{\circ} \mathrm{C}\right.$ for $8 \mathrm{~s})$, and extension $\left(72^{\circ} \mathrm{C}\right.$ for $\left.15 \mathrm{~s}\right)$. Fluorescence was measured continuously during the slow temperature rise to monitor the dissociation of the LightCycler Red 640-labeled sensor probe at the F2 channel. Water was used instead of DNA as a negative control.

\section{Results}

Sensitivity of the DNA extraction methods. Four different DNA extraction methods were evaluated for whole DNA purification from Brucella melitensis. Serial dilution of Brucella melitensis cells were suspended in either sterile water or whole blood to give a final cells count of 25 to $25000 \mathrm{CFU} / \mathrm{ml}$. DNA was extracted and the purified DNA was used as a template for PCR reaction. The sensitivity and efficacy was measured as the minimum number of $\mathrm{CFU}$ required to produce DNA showing a positive PCR. The results for the approximate sensitivity of each method are shown in Tables II and III. It was found that the MagNA Pure LC method was the most efficient and sensitive method as it showed positive PCR reaction with DNA extracted from as low as 25 and $100 \mathrm{CFU}$ suspended in one $\mathrm{ml}$ blood and

Table II

Sensitivities of different DNA extraction methods. Serial dilution of the Brucella melitensis cells was prepared in one ml blood. Total DNA was extracted using different methods and the purified DNA was used as template in PCR

\begin{tabular}{|l|c|c|c|c|c|c|c|c|c|}
\hline \multicolumn{1}{|c|}{ DNA extraction } & \multicolumn{6}{|c|}{ Count of Brucella cells (CFU/ml blood) } \\
\hline \multicolumn{1}{|c|}{ Methods } & 25000 & 6000 & 800 & 400 & 200 & 100 & 50 & 25 \\
\hline MagNA Pure LC & + & + & + & + & + & + & - & - \\
\hline QIAmp silica column & + & + & + & + & - & - & - & - \\
\hline GenomicPrep Blood & + & + & + & + & + & - & - & - \\
\hline Chelex resin & - & - & - & - & - & - & - & - \\
\hline
\end{tabular}

+: Positive PCR, -: Negative PC 
one $\mathrm{ml}$ water respectively, followed by GenomicPrep Blood method and QIAmp silica column purification method respectively (Table II and III). However none of the extracted DNA using Chelex resin was able to give positive PCR reaction. Based on these results the MagNA Pure LC method was selected for further analysis.

Detection of Brucella by conventional and real time PCR. Detection of Brucella melitensis by conventional PCR was investigated using four different targets. The results presented in Table IV and V and Figure 1 indicated that the B4-B5 amplification method was the most sensitive as it could amplify DNA extracted from as low as 25 and $100 \mathrm{CFU} / \mathrm{ml}$ suspended in one $\mathrm{ml}$ water and blood, respectively, followed by ISP1-ISP2 and F4-R2, respectively.
However, none of the bacterial DNA from whole blood or water gave a positive PCR using the JPRJPF method. Based on these results the B4-B5 method was used in analysis of the clinical samples. The sensitivity of the real-time PCR was determined using Brucella specific probes. The reaction was carried out using DNA extracted from serial dilution of bacterial cells suspended in blood and water. Real-time PCR was able to detect Brucella using DNA extracted from as low as 50 and $15 \mathrm{CFU}$ suspended in one $\mathrm{ml}$ blood and water respectively (Fig. 2).

Clinical samples. During the study period, 200 clinical blood specimens (160 patients and 40 controls) were tested for brucellosis by blood culture, optimum conventional PCR and real-time PCR. Among the 160 clinical samples tested, 89 specimens were
A

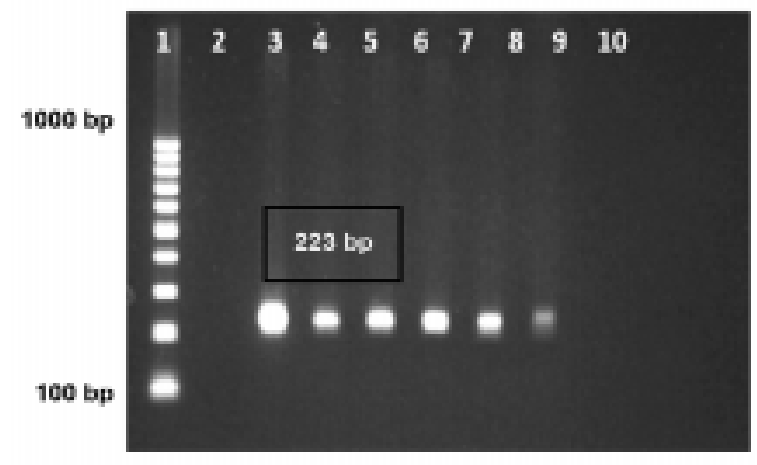

C

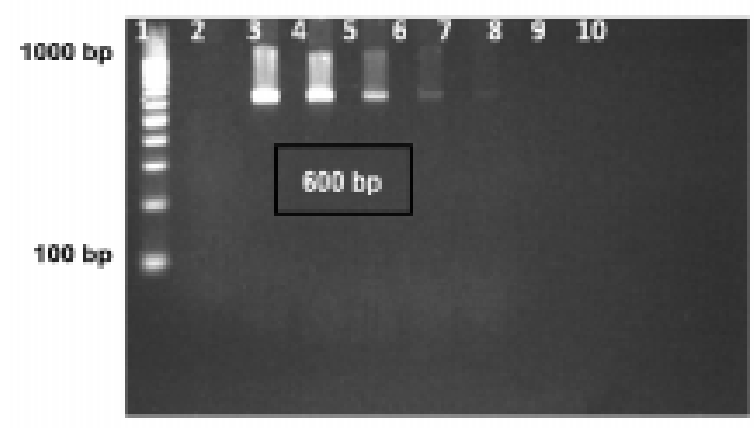

E

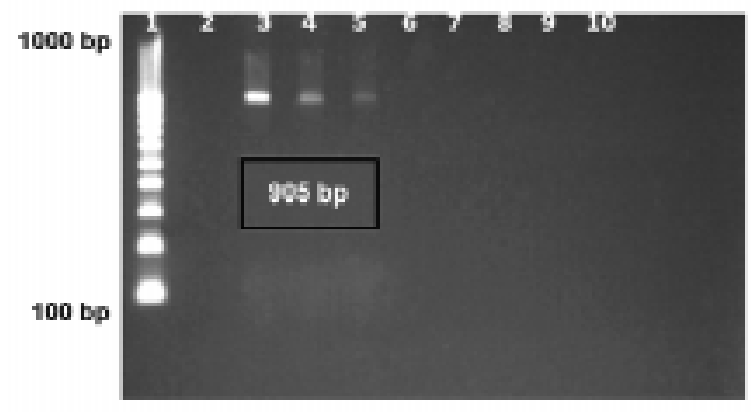

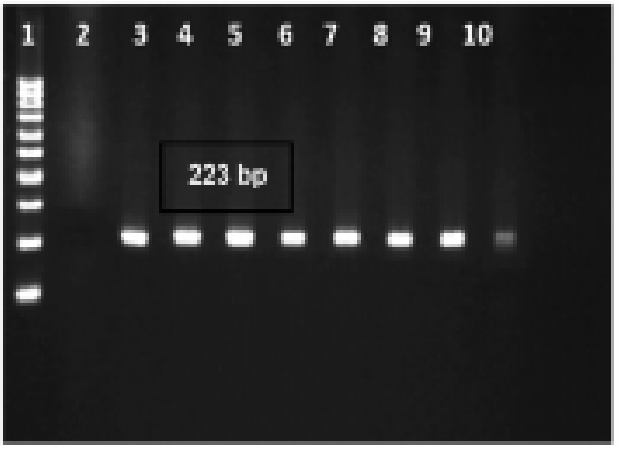

D

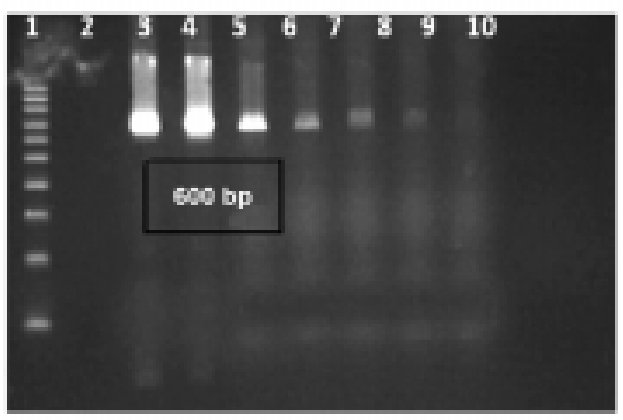

F

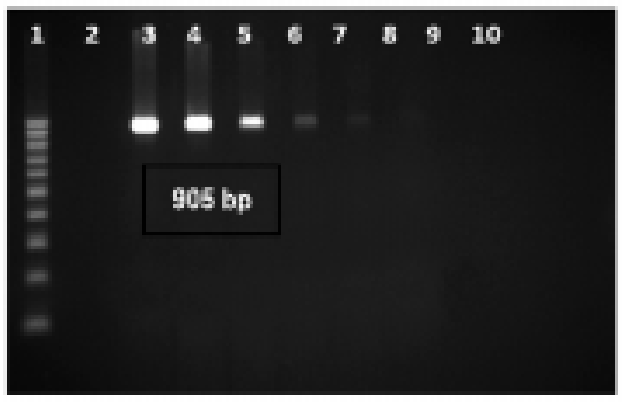

Fig. 1. Sensitivity of PCR using different targets for detection of Brucella sp.

Using B4-B5 and DNA extracted from and DNA extracted from serial dilutions of cells suspended in Blood (A) and water (B). Using ISP1-ISP2 and DNA extracted from serial dilutions cells suspended in blood (C) and water (D). Using F4-R2 and DNA extracted from cells suspended blood (E) and water (F). Lane 1: 100 bp Marker, 2: Negative control, 3: 25,000 CFU/ml, 4:6,000 CFU/ml, 5: $800 \mathrm{CFU} / \mathrm{ml}, 6: 400: \mathrm{CFU} / \mathrm{ml}, 7: 200 \mathrm{CFU} / \mathrm{ml}, 8: 100 \mathrm{CFU} / \mathrm{ml}, 9: 50 \mathrm{CFU} / \mathrm{ml}$ and 10: $25 \mathrm{CFU} / \mathrm{ml}$ 

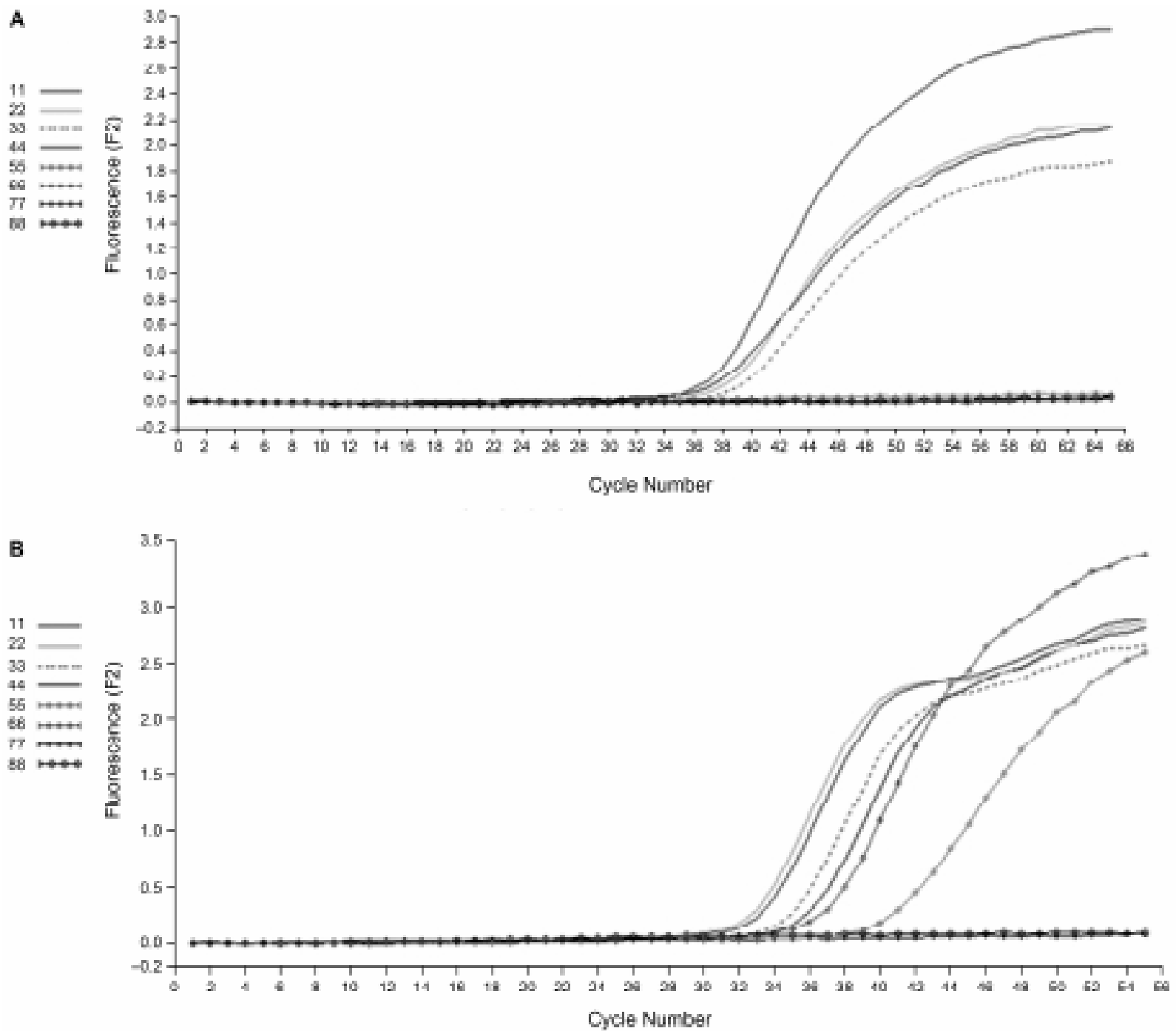

Fig. 2. Detection of Brucella by real time PCR

Fluorescence is plotted against number of PCR cycles to monitor amplification of different cells counts Brucella suspended in blood (A) and water (B) 1: $800 \mathrm{CFU} / \mathrm{ml}, 2: 200 \mathrm{CFU} / \mathrm{ml}, 3: 100 \mathrm{CFU} / \mathrm{ml}, 4: 50 \mathrm{CFU} / \mathrm{ml}, 5-25 \mathrm{CFU} / \mathrm{ml}, 6: 15 \mathrm{CFU} / \mathrm{ml}$, 7\&8: Negative control

blood culture positive for Brucella and 71 were negative but 9 of them were positive for other bacteria (six coagulase negative staphylococci, one Staphylococcus aureus, one Klebsiella spp. and one Acinatobacter spp). One of the blood culture positive for coagulase

Table III

Sensitivities of different DNA extraction methods. Serial dilution of the Brucella melitensis cells was prepared in one $\mathrm{ml}$ water. Total DNA was extracted using different methods and the purified DNA was used as template in PCR

\begin{tabular}{|l|c|c|c|c|c|c|c|c|}
\hline \multicolumn{1}{|c|}{ DNA extraction } & \multicolumn{9}{|c|}{ Count of Brucella cells (CFU/ml water) } \\
\hline \multicolumn{1}{|c|}{ Methods } & 25000 & 6000 & 800 & 400 & 200 & 100 & 50 & 25 \\
\hline MagNA Pure LC & + & + & + & + & + & + & + & + \\
\hline QIAmp silica column & + & + & + & + & + & + & - & - \\
\hline GenomicPrep Blood & + & + & + & + & + & + & + & - \\
\hline Chelex & + & + & + & - & - & - & - & - \\
\hline
\end{tabular}

+: Positive PCR, -: Negative PC negative staphylococcus (detection after $33 \mathrm{~h}$ ) was positive for Brucella by conventional PCR and light cycler PCR in blood, negative in serum and negative by blood culture. DNA was extracted from the 89 blood samples (which were found to be positive for Brucella by blood culture) and detection was carried

\section{Table IV}

Sensitivities of four PCR methods for detection of Brucella suspended in blood determined by amplifying the DNA extracted from different cells dilutions

\begin{tabular}{|l|c|c|c|c|c|c|c|c|}
\hline \multirow{2}{*}{ Methods } & \multicolumn{6}{|c|}{ Count of Brucella cells (CFU/ml blood) } \\
\cline { 2 - 11 } & 25000 & 6000 & 800 & 400 & 200 & 100 & 50 & 25 \\
\hline B4-B5 & + & + & + & + & + & + & - & - \\
\hline ISP1-ISP2 & + & + & + & + & + & - & - & - \\
\hline F4-R2 & + & + & + & - & - & - & - & - \\
\hline JPF-JPR & - & - & - & - & - & - & - & - \\
\hline
\end{tabular}

+: Positive PCR, -: Negative PC 
Table V

Sensitivities of four PCR methods for detection of Brucella suspended in water specimens determined by amplifying the DNA extracted from the dilution series

\begin{tabular}{|l|c|c|c|c|c|c|c|c|}
\hline \multirow{2}{*}{ Methods } & \multicolumn{9}{|c|}{ Count of Brucella cells (CFU/ml water) } \\
\cline { 2 - 10 } & 25000 & 6000 & 800 & 400 & 200 & 100 & 50 & 25 \\
\hline B4-B5 & + & + & + & + & + & + & + & + \\
\hline ISP1-ISP2 & + & + & + & + & + & + & - & - \\
\hline F4-R2 & + & + & + & + & + & - & - & - \\
\hline JPF-JPR & - & - & - & - & - & - & - & - \\
\hline
\end{tabular}

+: Positive PCR, -: Negative PC

Table VI

Detection of Brucella in blood and serum samples by conventional PCR in comparison to blood culture method

\begin{tabular}{|l|c|c|c|c|}
\hline \multicolumn{1}{|c|}{ Specimen } & Positive & False pos. & Sensitivity & Specificity \\
\hline Blood Culture & $89(89)$ & $0(40)$ & $100 \%$ & $100 \%$ \\
\hline Blood & $64(89)$ & $2(40)$ & $72 \%$ & $95 \%$ \\
\hline Serum & $48(89)$ & $0(40)$ & $54 \%$ & $100 \%$ \\
\hline
\end{tabular}

Table VII

Detection of Brucella spp. in blood and serum samples by real-time PCR in comparison to blood culture method

\begin{tabular}{|l|c|c|c|c|}
\hline \multicolumn{1}{|c|}{ Specimen } & Positive & False pos. & Sensitivity & Specificity \\
\hline Blood culture & $89(89)$ & $0(40)$ & $100 \%$ & $100 \%$ \\
\hline Blood & $69(89)$ & $0(40)$ & $77.5 \%$ & $100 \%$ \\
\hline Serum & $54(89)$ & $0(40)$ & $60 \%$ & $100 \%$ \\
\hline
\end{tabular}

out using optimum conditions of conventional PCR and real-time PCR. The results of conventional PCR showed that 64 out of 89 blood samples and 2 of the 40 control samples $(5 \%)$ were positive. In addition, 48 of the 89 serum samples were positive and none of the control samples were positive. The sensitivities of PCR detection in blood, serum and blood culture were 72,54 and $100 \%$, respectively, and the specificities were $95,100,100 \%$ respectively (Table VI). The results of detection of Brucella spp. using real-time PCR are shown in Table VII. It was found that 69 out of 89 blood samples were positive and 54 of the 89 serum samples $(60 \%)$ were positive and none of the control samples were positive. The sensitivities for blood, serum and blood culture were $77.5,60$ and $100 \%$ with specificities of 100,100 , $100 \%$, respectively.

\section{Discussion}

An accurate diagnosis of brucellosis is very important for treatment, control and eradication of brucellae and due to the prevalence of brucellosis in Saudi Arabia, an efficient and sensitive diagnostic method should be established for the control of brucellae in this population (Elfaki et al., 2005). PCR offers an alternative choice over the conventionally available methods for an accurate diagnosis of brucellosis. However, sufficient nucleic with removal of inhibitory substances is essential for optimal detection of the microbial pathogens by PCR. The aim of this study was to optimize the DNA extraction and PCR conditions for detection of Brucella spp. and apply the optimum conditions in the clinical samples and compare it with blood culture approach. Therefore four different DNA extraction methods were evaluated to purify total DNA from Brucella melitensis. Although blood is known to possess substances inhibitory to PCR, the DNA purification methods used in this study (except chelex resin method) were successful in eliminating these inhibitors, the most sensitive and efficient one being the MagNA Pure LC method showing positive PCR reaction with DNA extracted from as low as 25 and $100 \mathrm{CFU}$ suspended in one $\mathrm{ml}$ blood and one $\mathrm{ml}$ water respectively. The detection of bacterial DNA in blood specimens by PCR usually requires sensitive DNA amplifying method with sensitive primers and optimized PCR conditions because of the presence of human DNA and inhibitors in blood (Bricker, 2002; Bogdanovich et al., 2004). With the aim of finding the most efficient and sensitive methods for detection of Brucella DNA in blood specimens, four DNA amplifying methods were evaluated using four primers pairs including B4-B5, ISP1-ISP2, F4-R2 and JPF-JPR. The results indicated that the detection limit varied between 25 to $800 \mathrm{CFU} / \mathrm{ml}$, depending on the amplifying method (except JPF-JPR method). The B4-B5 amplification method was the most sensitive one as it could amplify DNA extracted from as a low as 25 and $100 \mathrm{CFU} / \mathrm{ml}$ suspended in one $\mathrm{ml}$ water and blood respectively, followed by ISP1-ISP2 and F4-R2, respectively. This result is consistent with that previously reported by Elfeki et al. (2005) where PCR using primers B4-B5 was the most sensitive one for detection of Brucella spp. However in another study by Navarro et al. (2002) for comparison of three PCR methods for detection of Brucella, F4/R2 was the most sensitive primers. Furthermore the sensitivity of the real-time PCR was determined using Brucella specific probes. The reaction was carried out using DNA extracted from serial dilution of bacterial cells suspended in blood and water. Real-time PCR was even more sensitive than conventional PCR as it was able to detect Brucella spp. using DNA extracted from as low as $50 \mathrm{CFU} / \mathrm{ml}$ blood $15 \mathrm{CFU} / \mathrm{ml}$ water.

The best DNA extraction method was used to extract DNA from the clinical samples and optimum conventional PCR conditions, RT-PCR and blood culture were compared for detection of Brucella spp. in the clinical blood samples. It was found that $72 \%$ 
and $54 \%$ of the positive blood culture was detected by PCR with specificity of $95 \%$ and $54 \%$ in blood and serum, respectively. The use of PCR for the detection of Brucella DNA in blood samples of certain groups of patients with brucellosis has been previously studied with sensitivity in the range of 50\% to $100 \%$ (Mattar et al., 1996; Navarro et al., 1999; Zerva et al., 2001). Several systems of real-time PCR have been developed. They are user-friendly, rapid, and free of contamination. Moreover, these PCRs overcome the conventional PCR by allowing quantification of the targeted copies in the specimen (Newby et al., 2003; Probert et al., 2004). Evaluation of the real-time PCR for detection of Brucella spp. in the clinical blood samples showed excellent specificity and good sensitivity. The real-time PCR confirmed $77.5 \%$ of the results obtained with the blood culture assays with specificity of $100 \%$. In this study it appears that the real-time PCR has greater sensitivity and specificity than conventional PCR.

Conclusions. In conclusion comparison of blood culture, conventional PCR conditions and RT-PCR for detection for detection of Brucella spp. in the clinical blood samples indicated that PCR amplification technology is promising method for the detection of Brucella in clinical samples with high sensitivity and specificity close to that reported by conventional blood culture. Although the PCR detection of Brucella spp. using peripheral blood is not without difficulties, it presents considerable advantages. Compared to standard bacteriological methods, the PCR assays are safer and more rapid to perform. Therefore, these assays may be important diagnostic tools to detect Brucella spp.

\section{Acknowledgment}

This work was financially supported by Deanship of Scientific Research, King Saud University. The authors are gratefully acknowledged for this support

\section{Literature}

Abdoel T., I.T. Dias, R. Cardoso and H.L. Smit. 2008. Simple and rapid field tests for brucellosis in livestock. Vet. Microbiol. 130: 312-319.

Baddour M.M. and D.H. Alkhalifa. 2008. Evaluation of three polymerase chain reaction techniques for detection of Brucella DNA in peripheral human blood. Can. J. Microbiol. 54: 352-357.
Bogdanovich T., M. Skurnik, P.S. Lubeck, P. Ahrens and J. Hoorfar. 2004. Validated 5' nuclease PCR assay for rapid identification of the genus Brucella. J. Clin. Microbiol. 42: 2261-2263.

Bricker B.J. 2002. PCR as a diagnostic tool for brucellosis. Vet. Microbiol. 90: 435-446.

Cutler S.J., A.M. Whatmore and N.J. Commander. 2005. Brucellosis - new aspects of an old disease. J. Appl. Microbiol. 98: $1270-128.1$

Diaz R. and I. Moriyo. 1989. Laboratory techniques in the diagnosis of human brucellosis. In: Brucellosis: Clinical and Laboratory Aspects (Young, E.J. and Corbel, M.J., Eds.), pp. 73-83. CRC Press, Boca Raton, FL.

Elfaki M.G., T. Uz-Zamana, A.A. Al-Hokailb and S.M. Nakeeba. 2005. Detection of brucella DNA in sera from patients with brucellosis by polymerase chain reaction. Diagnos. Microbiol. and Infect. Dis. 53: 1-7.

Godfroid J. 2002. Brucellosis in Wildlife. Rev. Sci. Tech. Int. Epiz. 21: 277-286.

Hinić V., I. Brodard, A. Thomann, Ž. Cvetnić, P.V. Makaya, J. Frey and C. Abril. 2008. Novel identification and differentiation of Brucella melitensis, B. abortus, B. suis, B. ovis, B. canis, and $B$. neotomae suitable for both conventional and real-time PCR systems. J. Microbiol. Methods. 75: 375-378.

Mattar G.M., I.A. Khneisser and A.M. Abdelnoor. 1996. Rapid laboratory confirmation of human brucellosis by PCR analysis of a target sequence on the 31-Kilodalton Brucella antigen DNA. J. Clin. Microbiol. 34: 477-478.

Navarro E., J. Escribano, J.A. Fernandez and J. Solera. 2002. Comparison of three different PCR methods for detection of Brucella spp. in human blood samples. FEMS Immun. Med. Microbiol. 34: 147-151.

Navarro E., J.A. Fernandez and J. Solera. 1999. PCR assay for diagnosis of human brucellosis. J. Clin. Microbiol. 37: 1654-1655. Newby D.T., T.L. Hadfield and F.F Roberto. 2003. Real-time PCR detection of Brucella abortus: a comparative study of SYBR Green I, 5'-exonuclase, and hybridization probe assays. Appl. Environ. Microbiol. 69: 4753-4759.

Probert W.S., K.N. Schrader, N.Y. Khuong, S.L. Bystrom and M.H. Graves. 2004. Real time multiplex PCR assay for detection of Brucella spp., B. abortus, and B. melitensis. J. Clin. Microbiol. 42: 1290-1293.

Redkar R., S. Rose, B. Bricker and V. Del Vecchio. 2001. Realtime detection of Brucella abortus, Brucella melitensis and Brucella suis. Mol. Cell. Prob. 15: 4352

Sauret J.M. and N. Villissova. 2002. Human brucellosis. J. Am. Board. Pract. 15: 401-406.

Yagupsky P. 1999. Detection of Brucella in blood cultures. J. Clin. Microbiol. 37: 3437-3342

Yugupsky P. 2004. Use of the BACTEC MYCO/F LYTIC medium for detection of Brucella melitensis bacteremia. J. Clin. Microbiol. 42: 2207-2208.

Zerva L., K. Bourantas, S. Mitka, A. Kansouzidou and N.J. Legakis. 2001. Serum is the preferred clinical specimen for diagnosis of human brucellosis by PCR. J. Clin. Microbiol. 39: $1661-1664$. 